\title{
Editorial overview: Physiology and metabolism: Harnessing genetic variation in metabolic traits to understand trait evolution and improve the sustainability of crop production
}

\author{
Elizabeth A. Ainsworth and Elizabete Carmo-Silva
}

Elizabeth A. Ainsworth, USDA ARS Global Change and Photosynthesis Research Unit, $1201 \mathrm{~W}$. Gregory Drive, Urbana, IL 61801, USA; email: lisa.ainsworth@ars.usda.gov

Elizabeth A. Ainsworth is a USDA ARS scientist in the Global Change and Photosynthesis Research Unit and Adjunct Professor of Plant Biology at the University of Illinois in Urbana-Champaign. Her research aims to improve ozone tolerance in major crops, adapt crops to rising atmospheric carbon dioxide concentrations, and identify genetic variation in crop canopy architecture and photosynthesis.

Elizabete Carmo-Silva, Lancaster University, Lancaster Environment Centre, Lancaster, LA1 4YQ, UK; email: e.carmosilva@lancaster.ac.uk

Elizabete Carmo-Silva is a Senior Lecturer and Principal Investigator at the Lancaster Environment Centre. Her laboratory studies the regulation of the $\mathrm{CO}_{2}$-fixing enzyme Rubisco. Her research aims to improve global food security and optimize resource use by maximizing crop photosynthetic efficiency in fluctuating environments.

At a time of unprecedented challenges for humankind and the environment we live in, understanding, preserving and exploiting genetic diversity in metabolic traits offers an opportunity to improve the sustainability of crop production while protecting ecosystems biodiversity. Plants are sessile organisms and evolve mechanisms of adaptation to the surrounding environment that enhance their fitness and chances of survival. With the climate becoming increasingly unpredictable and volatile, physiological and metabolic plasticity enables plants to thrive in natural ecological and agricultural environments. In this editorial we provide an overview of the potential to exploit genetic diversity to address the challenges of improving the sustainability of crop production and conserving biodiversity.

Gaining fundamental understanding of metabolic trait evolution and adaptation relies on investigation of genetic variation, the naturally occurring differences in DNA sequence observed within a species. Such differences in sequence arise from random mutations and may be passed on to subsequent generations. Some of these mutations may improve fitness and therefore become more common in a population while others may reduce an individual's fitness and are likely to be lost over time [1]. The result of the evolution of biochemical and metabolic traits is increased complexity and tremendous plant diversification [2]. Our ability to understand how evolution resulted in complex agriculturally and ecologically important traits depends upon investigation of genetic variation. Articles in this issue explore the evolution of genetic variation in $\mathrm{C}_{3}$ and $\mathrm{C}_{4}$ photosynthesis [3,4], production of an incredible diversity of specialized metabolites [5], and adaptation to the circadian clock [6]. These studies highlight the development of an enabling and rich toolbox of genomic, metabolomic and proteomic approaches for quantifying variation in complex and diverse phenotypic traits.

Additionally, there is vast and underutilized genetic diversity within and across the relatively small number of agronomically important plants. Of the more than 14,000 edible plant species on the planet, it is estimated that only 150-200 are used by humans [7], and only three species (rice, maize and wheat) contribute $60 \%$ of the calories consumed by humans [8]. Loss of genetic diversity occurred during domestication and through plant breeding, and imposes a genetic bottleneck on crops [9]. Although 
variation in metabolic traits is greater across different species (interspecies), intraspecies variation exists $[3,10]$ and can be exploited for crop improvement in breeding programs. By accessing landraces and wild relatives, allelic variation lost during breeding can be re-introduced into crop germplasm [11]. This potential for legumes, the third-largest plant family on the planet, is explored by Zhang and co-authors who describe recent progress in using genetic variation in wild legume species to improve biotic stress resistance, abiotic stress tolerance, nutrition, and phytocompounds in crops [12].

Improving the sustainability of agriculture is a critical need if we are to address the growing demands of a more populous and affluent global population, as well as maintain functional natural ecosystems [13]. Critically, increasing sustainability of agriculture has a major impact on climate regulation as agriculture is an important contributor of greenhouse gases and driver of global change. Genetic variation in traits that can improve resource use efficiency in crops is well established, and articles in this issue address the potential to harness natural variation to improve water use efficiency [14], photosynthetic efficiency [10] and nitrogen use efficiency in cereals [15].

The world is warming and the climate is becoming increasingly volatile and unpredictable. Efforts have been made to identify protein isoforms available in nature that operate optimally at warm temperatures. In this issue, Galmés and co-authors provide an overview of natural diversity in the temperature response of the $\mathrm{CO}_{2}$-fixing enzyme Rubisco and show that replacing the native enzyme present in wheat and maize with enzymes that show superior performance at warm temperatures may enhance and future-proof the productivity of these crops by doubling their carbon assimilation potential [16]. More importantly, it is becoming increasingly apparent that photosynthetic optimality needs to be adjusted to a broad spectrum of temperatures if crops are to be productive in an increasingly volatile growing environment.

Although our understanding of genetic variation in plant metabolic processes such as photosynthesis has greatly improved over the past decades, we are still unable to measure accurately and with sufficient throughput the efficiency of photosynthetic responses to rapid changes in the environment. Murchie and co-authors [17] review evidence suggesting that dynamic changes in photosynthesis in response to rapidly changing environmental cues (i.e., the "photosynthome") significantly impact crop yields. Moreover, the regulation of photosynthetic metabolism is still poorly understood. As highlighted by Rosa and Abreu in this issue, genetic diversity exists in regulatory mechanisms affecting plant physiology and metabolism, and a better understanding of such regulatory mechanisms will unlock the potential to exploit novel strategies to improve crop performance [18].

Unfortunately, land use change, urbanization encroaching on natural spaces, and loss of habitat with global change challenge the protection of genetic diversity within the world's species. The planet is currently in the midst of the sixth mass species extinction event, losing species at an estimated rate 1001000 times greater than during the Holocene [19,20,21]. With these species loss also comes the loss of genetic variation and the potential loss of opportunities to understand trait evolution and adaptation. The articles in this issue serve as an important reminder of the need to conserve genetic variation.

\section{Acknowledgements}

We thank Ottoline Leyser and James Carrington for the invitation to guest edit the 2019 Physiology and Metabolism issue, the authors and reviewers for their contributions, and the Editorial Manager Alison Langestraat for guidance and support. 


\section{References}

1. Kerwin R, Feusier J, Corwin J, Rubin M, Lin C, Muok A, Larson B, Li B, Joseph B, Francisco M et al:: Natural genetic variation in Arabidopsis thaliana defense metabolism genes modulates field fitness. eLife 2015, 4:e05604.

2. Mint Evolutionary Genomics Consortium: Phylogenomic mining of the mints reveals multiple mechanisms contributing to the evolution of chemical diversity in Lamiaceae. Molecular Plant 2018, 11:1084-1096.

3. Flood P: Using natural variation to understand the evolutionary pressures on plant photosynthesis. Curr Opin Plant Biology 2019, 49:xx-xx.

4. Stata M, Sage TL, Sage RF: Mind the gap: the evolutionary engagement of the C4 metabolic cycle in support of net carbon assimilation. Curr Opin Plant Biol 2019, 49:27-34.

5. Fan P, Leong BJ, Last RL: Tip of the trichome: evolution of acylsugar metabolic diversity in Solanaceae. Curr Opin Plant Biol 2019, 49:8-16.

6. Salmela MJ, Weinig C: The fitness benefits of genetic variation in circadian clock regulation. Curr Opin Plant Biol 2019, 49:xx-xx.

7. McCouch S: Feeding the future. Nature 2013, 499:23-24.

8. Willett W, Rockström J, Loken B, Springmann M, Lang T, Vermeulen S, Garnett T, Tilman D, DeClerk F, Wood A, et al.: Food in the Anthropocene: the EAT-Lancet Commission on healthy diets from sustainable food systems. The Lancet 2019, 393:10170. DOI:10.1016/S01406736(18)31788-4.

9. Esquinas-Alcázar J: Protecting crop genetic diversity for food security: political, ethical and technical challenges. Nat Rev Genet 2005, 6:946-953.

10. Tanaka Y, Adachi S, Yamori W: Natural genetic variation of the photosynthetic induction response to fluctuating light environment. Curr Opin Plant Biol 2019, 49:52-59.

11. Dempewolf H, Baute G, Anderson J, Kilian B, Smith C, Guarino L: Past and future use of wild relatives in crop breeding. Crop Sci 2017, 57:1070-1082.

12. Zhang H, Yasmin F, Song B-H: Neglected treasures in the wild - legume wild relatives in food security and human health. Curr Opin Plant Biol 2019, 49:17-26.

13. Rockström J, Williams J, Daily G, Noble A, Matthews N, Gordon L, Wetterstrand H, DeClerk F, Shah M, Steduto P, et al.: Sustainable intensification of agriculture for human prosperity and global sustainability. Ambio 2017, 46:4-17.

14. Faralli M, Matthews J, Lawson T: Exploiting natural variation and genetic manipulation of stomatal conductance for crop improvement. Curr Opin Plant Biol 2019, 49:1-7.

15. Hawkesford MJ, Griffiths S: Exploiting genetic variation in nitrogen use efficiency for cereal crop improvement. Curr Opin Plant Biol 2019, 49:35-42.

16. Galmés J, Capó-Bauçà $\mathrm{S}$, Niinemets Ü, Iñiguez $\mathrm{C}$ : Potential improvement of photosynthetic $\mathrm{CO}_{2}$ assimilation in crops by exploiting the natural variation in the temperature response of Rubisco catalytic traits. Curr Opin Plant Biology 2019, 49:60-67.

17. Murchie EH, Kefauver S, Araus JL, Muller O, Rascher U, Flood PJ, Lawson T: Measuring the dynamic photosynthome. Annals Bot 2018, 122:207-220.

18. Rosa MT, Abreu IA: Exploring the regulatory levels of SUMOylation to increase crop productivity. Curr Opin Plant Biology 2019, 49:43-51.

19. Barnosky AD, Hadly EA, Bascompte J, Berlow EL, Brown JH, Fortelius M, Getz WM, Harte J, Hastings A, Marquet PA, et al.: Approaching a state shift in Earth's biosphere. Nature 2012; 486: $52-58$. 
20. Ceballos G, Ehrlich PR, Dirzo R: Biological annihilation via the ongoing sixth mass extinction signaled by vertebrate population losses and declines. Proc Natl Acad Sci USA 2017; 114 : E6089-96.

21. Pimm SL, Jenkins CN, Abell R, Brooks TM, Gittleman JL, Joppa LN, Raven PH, Roberts CM, Sexton JO: The biodiversity of species and their rates of extinction, distribution, and protection. Science 2014; 344: 1246752. 